\title{
Diabetes mellitus and the nervous system
}

\author{
P J Watkins, P K Thomas
}

Diabetes mellitus is a disorder in which the concentration of blood glucose is persistently raised above the normal range. It occurs either because of a lack of insulin or because of the presence of factors which oppose the action of insulin. Hyperglycaemia results from insufficient insulin action. There are many associated metabolic abnormalities-notably, the development of hyperketonaemia when there is a severe lack of insulin, together with alterations of fatty acids, lipids, and protein turnover. Diabetes is a permanent condition in all but a few special situations in which it can be transient.

A wide variety of disturbances affecting the central and peripheral nervous systems, either directly or indirectly, may be encountered in patients with diabetes mellitus. This short selective review concentrates on recent progress in the delineation of the clinical features of the neurological syndromes related to diabetes and their management. It will deal, sequentially, with the classification of diabetes, a listing of some genetic disorders that may be accompanied by diabetes, the consequences of acute metabolic decompensation, and somatic and autonomic neuropathies, cerebrovascular disease, certain infections that have a particular association with diabetes and, finally, congenital malformations.

Diabetic Department, King's College Hospital, London, UK P J Watkins

University

Department of Clinical Neurosciences, Royal Free Hospital School of Medicine, London, UK

P K Thomas

Correspondence to: Professor PK Thomas, University Department of Clinical Neurosciences, Royal Free Hospital School of Medicine, Rowland Hill Street, London NW3 2PF, UK. Telephone 0044171 8302869 ; fax 0044171431 1577.

Received 10 March 1998 and in revised form 19 May 1998 Accepted 1 June 1998

\section{Classification}

The division of diabetes into two major types has long been known. The current classification ${ }^{1}$ (table 1) distinguishes type 1 (otherwise known as insulin dependent diabetes mellitus, IDDM) and type 2 (non-insulin dependent diabetes mellitus, NIDDM). This classification is important because the two types are distinct both in causation and management and is thus of direct clinical relevance.

In Western Europe, type 1 diabetes accounts for perhaps $10 \%-20 \%$ of all patients, although in the world at large there seems to be an extraordinary increase in type 2 diabetes from an estimated 124 million at present to a predicted 221 million by the year 2010 with only $3 \%$ of all patients with type 1 diabetes. The many other types of diabetes, either secondary to other causes or specific genetic syndromes, account for only a small proportion of patients (table 1).

\section{Some genetic disorders associated with diabetes (table 1)}

MITOCHONDRIAL DISORDERS

Mitochondria possess their own DNA (mtDNA), which is arranged as a discrete circular molecule encoding for a proportion of the peptides required for the components of the respiratory chain. MtDNA is passed exclusively down the maternal line of inheritance. There are several reported mutations in the tRNA Leu(UUR) gene, the one most often found occurring at position $3243 .^{23}$ These mutations are associated with maternally inherited diabetes combined with sensorineural deafness (MIDD) and accounts for around two type 2 diabetic patients in every 1000 and less than half that number among type 1 patients. Diabetes has also been reported in patients with the same mutation causing the MELAS syndrome - that is, patients with associated myopathy, encephalopathy, lactic acidosis, and stroke-like episodes, and in the Kearns-Sayre syndrome.

Mitochondrial related diabetes usually presents at between 30 and 40 years of age and is due more to impaired insulin secretion than insulin resistance. ${ }^{4}$ Some patients come to need insulin treatment and some can even develop diabetic ketoacidosis. As well as deafness, other neuromuscular features are sometimes seen in diabetic patients with this mutation: some may have a myopathy (with ragged red fibres), and a group of five patients with insulin induced painful neuropathy has been described with the 3243 mutation. ${ }^{5}$ The prevalence of complications seems similar to that among diabetic patients without this mutation, so that meticulous control of diabetes in this condition is just as important as in others.

\section{FRIEDREICH'S ATAXIA}

Friedreich's ataxia is an autosomal recessive spinocerebellar degeneration that has recently been shown to be due to an intronic GAA repeat expansion on chromosome $9 \mathrm{q}^{6}$ resulting in a defect in its gene product frataxin. The function of frataxin is unknown but there is evidence that it is a mitochondrial protein $^{7}$ and that its deficiency leads to abnormal energy metabolism. ${ }^{8}$ Between $10 \%$ and $20 \%$ of patients with Friedreich's ataxia develop diabetes. ${ }^{9}$ This always begins after the onset of the neurological symptoms and is insulin dependent. Ketoacidosis may occur. There is some suggestion for 
Table 1 Aetiological classification of diabetes mellitus

Type 1 diabetes ${ }^{\star}$ (B cell destruction, usually leading to absolute insulin deficiency. Immune mediated

Idiopathic

Type 2 diabetes ${ }^{\star}$ (may range from predominantly insulin resistance with relative insulin deficiency to a predominantly secretory defect with insulin resistance)

Other specific types

Genetic defects of $\beta$ cell function

Chromosome 12, HNF-1 (formerly MODY3)

Chromosome 7, glucokinase (formerly MODY2)

Chromosome 20, HNF-4 (formerly MODY1)

Mitochondrial DNA

Others

Genetic defects in insulin action

Type A insulin resistance

Leprechaunism

Rabson-Mendenhall syndrome

Lipoatrophic diabetes

Others

Diseases of the exocrine pancreas

Pancreatitis

Trauma/pancreatectomy

Neoplasia

Cystic fibrosis

Haemochromatosis

Fibrocalculous pancreatopathy

Others

Endocrinopathies

Acromegaly

Cushing's syndrome

Glucagonoma

Pheochromocytoma

Hyperthyroidism

Somatostatinoma

Aldosteronoma

Others

Drug or chemical induced

Glucocorticoids

Pentamidine

Nicotinic acid

Vacor

Thyroid hormone

Diazoxide

$\beta$-adrenergic agonists

Thiazides

Phenytoin

Interferon

Others

Infections

Congenital rubella

Cytomegalovirus

Others

Uncommon forms of immune mediated diabetes

"Stiff man" syndrome, associated with antibodies to

glutamic acid decarboxylase (GAD)

Anti-insulin receptor antibodies

Others

Other genetic syndromes sometimes associated with diabetes Down's syndrome

Klinefelter's syndrome

Turner's syndrome

Wolfram syndrome

Friedreich's ataxia

Lawrence-Moon-Biedl syndrom

Myotonic dystrophy

Porphyria

Prader Willi syndrome

Others

Gestational diabetes mellitus

$\star$ Patients with any form of diabetes may require insulin treatment at some stage of their disease. Such use of insulin does not, of itself, classify the patient.

clustering of diabetes within families. It is important that patients with Friedreich's ataxia should be tested for glycosuria at roughly 6 monthly intervals.

\section{WOLFRAM SYNDROME}

Wolfram syndrome is a rare recessively inherited form of insulin dependent diabetes (type 1) associated with diabetes insipidus, optic atrophy causing blindness and deafness (hence DIDMOAD syndrome)..$^{10}$ Although best known as an endocrine disorder, the clinical features are predominantly neurological and include late onset cerebellar ataxia, psychiatric disturbances, anosmia, apnoeic episodes, and startle myoclonus. Its course is one of gradual decline and premature death. The exact genetic defect is not known but there is evidence of linkage to chromosome 4, and evidence for a mitochondrial defect has also been presented.

\section{Acute metabolic decompensation}

DIABETIC KETOACIDOSIS

Diabetic ketoacidosis occurs in type 1 diabetes either as a result of absolute or relative insulin lack. It occurs either as the presentation of newly diagnosed diabetes, as a consequence of omitting insulin or inappropriately reducing its dose, or in the presence of intercurrent illness, especially acute infections when the insulin is not increased in time to conteract the relative insulin resistance. Patients with ketoacidosis may be drowsy but are not normally unconscious unless in extremis.

\section{HYPEROSMOLAR ENCEPHALOPATHY}

Hyperosmolar non-ketotic "coma" (HONK) usually occurs in older patients with type 2 diabetes, often in AfroCaribbean patients, and much less often in insulin dependent patients. The presence of a small amount of circulating insulin is sufficient to suppress ketogenesis but not to prevent hyperglycaemia. Extreme hyperglycaemia (range 40-80 $\mathrm{mmol} / \mathrm{l}$ ) combined with hypernatraemia results in considerable hyperosmolality.

The level of consciousness is related to the degree of hyperosmolality. Patients are not infrequently stuporose, and sometimes unconscious. Focal or generalised seizures sometimes occur and very rarely dystonic movements are witnessed. These neurological features resolve completely when the metabolic state has returned to normal.

\section{CEREBRAL OEDEMA}

Cerebral oedema is a well known but rare and potentially fatal complication of diabetic ketoacidosis, which occurs during apparently successful treatment. Children are particularly vulnerable and some $1 \%$ to $2 \%$ may develop clinically apparent cerebral oedema during treatment. The exact cause is uncertain but electrolyte exchanges in and out of cells with a net influx of sodium into the cells might be responsible. ${ }^{11}$ Cerebral oedema usually occurs within 8 to 24 hours after starting treatment with intravenous fluids and insulin. Excessively rapid correction of hyperosmolality or the use of hypotonic saline are thought to be precipitating factors. Patients who have shown every sign of recovery then unexpectedly decline. Those who show clinical signs of raised intracranial pressure or cerebral herniation are unlikely to recover. The use of mannitol or dexamethasone is advocated but evidence of their effectiveness is lacking.

\section{HYPOGLYCAEMIA $^{12}$}

Most patients treated with insulin, and some on excessive doses of sulphonylureas, experience hypoglycaemia at some time. Indeed, it repre- 
sents the sole major hazard of insulin treatment. Patients may experience symptoms of hypoglycaemia when the blood glucose is less than 3 $\mathrm{mmol} / \mathrm{l}$ although some who have lost their alerting symptoms may pass below this threshold without warning.

Symptoms and signs of hypoglycaemia are summarised in table 2. Most patients develop appropriate warning symptoms, many of which represent autonomic stimulation, and they are capable of taking corrective action by swallowing simple sugars to correct the hypoglycaemia. The onset of neuroglycopenic features is however, associated with diminished cognitive function which may lessen the capacity to take corrective measures. Untreated hypoglycaemia can then progress to restless or even violent behaviour, unconsciousness, seizures, and (rarely) reversible hemiplegia.

Loss of warning of hypoglycaemia is the problem which all insulin treated diabetic patients dread. It is common and about 1 in 10 patients each year need assistance from another person. The mechanisms which underlie this state are poorly understood, although it is now clear that it is much commoner in those who have frequent hypoglycaemic episodes associated with tight control of their diabetes. In this situation the threshold for sympathetically driven counter regulatory responses and hypoglycaemic symptoms is reduced below that at which cognitive impairment takes place. This abnormal sequence can have disastrous effects for patients, especially in potentially dangerous situations such as driving; it is, however, reversible and hypoglycaemic warning symptoms can be restored to their normal threshold if meticulous attention is paid to the elimination of all hypoglycaemic events. Warning can be restored by the infusion of other metabolites such as lactate and there are now extensive research projects in progress to discover ways of avoiding and correcting loss of warning of hypoglycaemia. There is no evidence that preparations of human insulin provoke this problem more readily than the animal insulins, although when patients think this to be the case it is standard practice to change them to animal insulin at the same time as taking all the other precautions needed to avoid hypoglycaemia.

Death does not normally occur during hypoglycaemic episodes even when they are

Table 2 Clinical features of hypoglycaemia

\begin{tabular}{|c|c|}
\hline Early warning: & $\begin{array}{l}\text { Shaking, trembling } \\
\text { Sweating } \\
\text { Tingling in lips and tongue } \\
\text { Hunger } \\
\text { Palpitations } \\
\text { Headache (occasionally) }\end{array}$ \\
\hline $\begin{array}{l}\text { Neuroglycopenia: } \\
\text { Mild }\end{array}$ & $\begin{array}{l}\text { Impaired cognitive dysfunction } \\
\text { Mild diplopia } \\
\text { Dysarthria }\end{array}$ \\
\hline More advanced & $\begin{array}{l}\text { Confusion } \\
\text { Change of behaviour } \\
\text { Truculence } \\
\text { Naughtiness in children }\end{array}$ \\
\hline Unconsciousness & $\begin{array}{l}\text { Restlessness with sweating } \\
\text { Seizures, especially in children } \\
\text { Hemiplegia, especially in elderly } \\
\text { patients (but rare) }\end{array}$ \\
\hline
\end{tabular}

severe. The profound and protracted hypoglycaemia resulting from deliberate insulin overdosage can, however, be fatal but many sufferers recover, often with apparent lack of intellectual loss. The cause of the very rare "dead in bed" syndrome described in some young type 1 patients is not known and only speculatively associated with hypoglycaemia and perhaps hypokalaemia as well. Whether intellectual decline occurs as a result of repeated hypoglycaemia is still debated; recurrent severe hypoglycaemia sufficient to cause convulsions in childhood might be detrimental in this regard but in general it is not.

Postmortem studies of hypoglycaemic brain injuries show a specific distribution of lesions. Temporal lobe and hippocampal cortical lesions are the most extensive whereas the brainstem, cerebellum, and spinal cord seem relatively resistant to hypoglycaemic damage.

\section{Neuropathies of diabetes}

Various different neuropathy syndromes may be encountered in patients with diabetes (table 3 ), this probably reflecting a range of underlying disease mechanisms. These syndromes can occur in isolation or in combination.

Neuropathies are common in both type 1 and type 2 diabetes and there are no major structural differences in the pathology of the nerves in the two diabetes types. However, there are some important clinical distinctions. Thus symptomatic autonomic neuropathic syndromes almost invariably occur in established long duration type 1 diabetic patients in middle age. By contrast the reversible mononeuropathies occur much more often in older men with type 2 diabetes. There are no known reasons for these clinical differences.

\section{HYPERGLYCAEMIC NEUROPATHY}

Patients with newly diagnosed or poorly controlled diabetes may experience uncomfortable dysaesthesiae or pain in the feet and lower legs, which rapidly resolve on establishment of euglycaemia. Diabetic nerve is known to be hypoxic. ${ }^{13}$ Experimental studies in rats have shown that hyperglycaemic but not normoglycaemic hypoxia gives rise to alterations in fast $\mathrm{K}^{+}$conductance and after potentials, related to axoplasmic acidification. ${ }^{14}$ This might contribute to the occurrence of positive symptoms by the generation of ectopic impulses. Nerve conduction velocity is reduced in poorly controlled diabetic patients and recovers rapidly with correction of the hyperglycaemia. ${ }^{15} 16$ The peripheral nerves also show an abnormal resistance to ischaemic

Table 3 Classification of the diabetic neuropathies

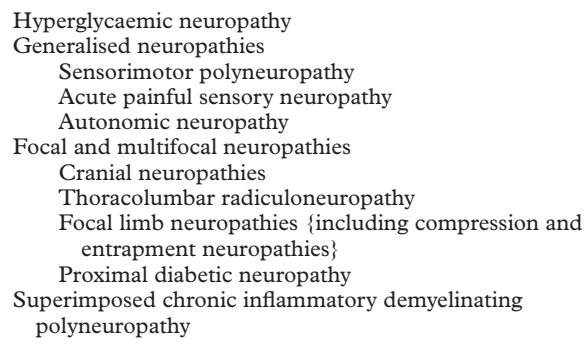


conduction failure ${ }^{17}$ which may be noticed by patients as a diminished tendency to develop ischaemic paraesthesiae on nerve compression. This is probably explicable in terms of a switch to anaerobic glycolysis in diabetic nerve. ${ }^{18}$

\section{DIABETIC SENSORY POLYNEUROPATHY}

This is the commonest form of diabetic neuropathy. It consists of a distal symmetric polyneuropathy which develops insidiously and which may be the presenting feature in type 2 diabetes. Reported studies on the prevalence of diabetic neuropathy are difficult to evaluate because of lack of consistency in the definition of neuropathy and in the methods employed for its detection. Observations on the incidence of neuropathy in patients attending diabetic clinics provide information on selected groups of patients. The most comprehensive population based investigation so far reported was undertaken by Dyck et $a l^{19}$ on residents of Rochester, MN, USA, with diabetes, of whom $26.8 \%$ were type 1 and $73.2 \%$ type 2 . Neuropathy was assessed by a combination of clinical and electrophysiological criteria. Of the patients with type 1 diabetes, $66 \%$ had some form of neuropathy, in $54 \%$ of whom it was diabetic polyneuropathy. In type 2 patients, $59 \%$ had various neuropathies, of which it was polyneuropathy in $45 \%$. Symptomatic neuropathy occurred in $15 \%$ of type 1 and $13 \%$ of type 2 patients. Severe polyneuropathy was encountered only in $6 \%$ of type 1 and $1 \%$ of type 2 patients; it was defined by weakness of dorsiflexion at the ankles such that the patients were unable to walk on their heels.

Diabetic polyneuropathy gives rise to sensory impairment with a "glove and stocking" distribution. All forms of sensation may be affected but there is evidence that those mediated by small myelinated and unmyelinated axons are affected first. ${ }^{20}$ Involvement of large fibres sufficient to cause sensory ataxia (diabetic pseudotabes) is now rare. Diabetic sensory polyneuropathy is often initially asymptomatic and is only discovered on neurological examination or when secondary complications develop, but it may present with numbness, pain, and paraesthesiae, mainly distally in the lower limbs. Autonomic neuropathy commonly coexists; minor distal motor involvement may be evident, but a significant distal motor neuropathy is uncommon.

In recent years, protocols have been developed to establish minimum criteria for the detection of diabetic neuropathy and criteria for its staging. ${ }^{21-23}$ These are essential for epidemiological studies and treatment trials. Less elaborate schemes are also available, suitable for the recognition of neuropathy during patient monitoring in diabetic clinics. ${ }^{24}$

Once established, diabetic sensory polyneuropathy is largely irreversible. ${ }^{25}$ The Diabetes Control and Complications Trial (DCCT) has shown that strict glycaemic control in patients with type 1 diabetes mellitus by continuous subcutaneous insulin infusion or multiple daily insulin injections reduces the risk of developing diabetic neuropathy, but at the cost of a threefold increase in severe hypoglycaemic epi- sodes. ${ }^{26}$ Whether strict glycaemic control would have a similar beneficial effect on the development of neuropathy in type 2 diabetes mellitus is unknown.

\section{Foot ulceration}

Diabetic sensory polyneuropathy is a major risk factor for the development of plantar ulceration because of the loss of protective sensation. ${ }^{27} 28$ Autonomic neuropathy which gives rise to anhidrosis and dry fissured skin also contributes, as does foot deformity, which leads to abnormal pressure distribution in the foot when standing or walking. ${ }^{29}$ Foot oedema also constitutes a major risk factor for foot ulceration. It may occur secondary to neuropathy. It probably results from loss of the venevasomotor reflex because of sympathetic failure. This reflex is normally activated on standing. Its loss results in the foot being unable to compensate for the rise in venous pressure when the patient is upright. Ephedrine administration can be helpful in the treatment of neuropathic oedema ${ }^{30}$ (see later). In the United Kingdom, foot ulceration is present in about $5 \%$ of the diabetic population. ${ }^{31}$ It is a major cause of disability and of occupancy of hospital beds. Monitoring patients for loss of protective sensation that could predispose to plantar ulcers, patient education for their prevention, and treatment should ulceration develop are vital aspects in the management of patients with diabetic neuropathy. ${ }^{32}$

Neuropathic osteoarthropathy (Charcot joints) Neuropathic joint degeneration affects about $10 \%$ of patients with neuropathy and more than $16 \%$ of those with a history of plantar ulceration. ${ }^{27}$ Recurrent trauma related to loss of protective joint sensation ${ }^{33}$ and osteopenia, ${ }^{34}$ possibly because of increased blood flow from sympathetic denervation, ${ }^{35}$ are the main predisposing factors. It has been noted that diabetic patients who have received a renal transplant have a substantially higher risk of developing neuropathic osteoarthropathy. ${ }^{36}$ The precise explanation is unknown but prolonged corticosteroid administration may be relevant. The most commonly affected joints are the tarsometatarsal, followed by the metatarsophalangeal and then the subtalar and ankle joints. ${ }^{37}$ Management is difficult. For an acutely inflamed joint, immobilisation and cessation of weight bearing for $2-3$ months is required to permit bone repair. Recently the use of bisphosphonates to inhibit osteoclast activity has been recommended. ${ }^{38}$

Unrecognised fractures occur in patients with diabetic sensory neuropathy. In a comparison of patients with diabetic neuropathy with and without a history of foot ulceration, non-neuropathic diabetic patients, and nonneuropathic controls, $22.2 \%$ of the neuropathic patients with a history of foot ulceration showed radiological evidence of fractures, usually of the metatarsal shafts. This was rare in the other three groups. ${ }^{39}$ 
ACUTE PAINFUL DIABETIC NEUROPATHY

This uncommon syndrome is distinct from diabetic sensory polyneuropathy. ${ }^{40}$ It is of acute or subacute onset and is characterised by burning or aching pain felt mainly in the lower limbs, and very rarely in the hands or over the upper limbs and trunk. It is accompanied by widespread cutaneous contact hyperaesthesia. Accompanying neurological signs are often not obtrusive with only slight distal sensory loss in the legs and depression of the ankle jerks. Motor signs do not occur. The relative lack of abnormal findings may suggest a psychogenic explanation for the symptoms. There may be associated depression. In the male, impotence may occur but otherwise autonomic manifestations are not prominent.

Acute painful diabetic neuropathy may be associated with severe rapid weight $\operatorname{loss}^{40} 41$ and has been described in girls with anorexia nervosa. ${ }^{42}$ It may also follow the institution of tight glycaemic control. ${ }^{43}{ }^{44}$ Treatment is by strict glycaemic control, even in those cases when it is precipitated by treatment. Recovery usually occurs over a period of 6-9 months.

\section{AUTONOMIC NEUROPATHY}

Damage to small myelinated and unmyelinated nerve fibres is one of the characteristics of diabetic neuropathy which gives rise to autonomic failure together with reduced thermal and pain sensation. Damage to small nerve fibres can occur either selectively or, more commonly, it accompanies impairment of other sensory modalities due to loss of large nerve fibres. The characteristics of neuropathies seen in diabetic patients are in part due to this pattern of fibre loss.

The occurrence of iritis requiring topical steroid treatment has been seen in association with symptomatic autonomic neuropathy. ${ }^{45}$ There is no clear explanation for this association. Nerve growth factor is known to accumulate in the denervated iris in experimental models and might serve as a mediator of the inflammatory responses. On the other hand, an immune mediated response may be responsible, as it is in other forms of iritis. There is also additional evidence that autoimmune mechanisms may play some part in the development of the small fibre damage involved in diabetic autonomic neuropathy. The presence of lymphocytic infiltration in

Table 4 Clinical features of autonomic neuropathy

\begin{tabular}{|c|c|c|c|}
\hline & Clinical syndromes & Other abnormalities & \\
\hline Cardiovascular & $\begin{array}{l}\text { Orthostatic hypotension } \\
\text { Neuropathic oedema }\end{array}$ & $\begin{array}{l}\text { High peripheral blood flow } \\
\text { Tachycardia } \\
\text { Rigidity/calcification of arteries }\end{array}$ & \\
\hline Sudomotor & $\begin{array}{l}\text { Nocturnal sweating } \\
\text { Gustatory sweating } \\
\text { Dry feet }\end{array}$ & & \\
\hline Genitourinary & $\begin{array}{l}\text { Impotence } \\
\text { Neurogenic bladder }\end{array}$ & & \\
\hline Gastrointestinal & $\begin{array}{l}\text { Diarrhoea } \\
\text { Gastroparesis }\end{array}$ & $\begin{array}{l}\text { Oesophageal motility } \\
\text { Gall bladder emptying }\end{array}$ & impaired \\
\hline Respiratory & $\begin{array}{l}\text { Arrests } \\
\text { ? Sudden deaths }\end{array}$ & $\begin{array}{l}\text { ? Sleep apnoea } \\
\text { Cough reflex reduced }\end{array}$ & \\
\hline $\begin{array}{l}\text { Skeletal } \\
\text { Eye }\end{array}$ & $\begin{array}{l}\text { Charcot arthropathy } \\
\text { Iritis }\end{array}$ & $\begin{array}{l}\text { Foot bone density reduced } \\
\text { Pupillary responses impaired } \\
\text { Pupil size reduced }\end{array}$ & \\
\hline Neuroendocrine & & $\begin{array}{l}\text { Catecholamines } \\
\text { Glucagon } \\
\text { Pancreatic polypeptide }\end{array}$ & reduced \\
\hline
\end{tabular}

autonomic tissues examined at necropsy, ${ }^{46}$ together with circulating immune complexes and activated $\mathrm{T}$ cells, all support this concept. Autoantibodies to the vagus nerve and cervical sympathetic ganglion in insulin dependent diabetic patients have also been found, although their exact relation with neuropathy remains uncertain.

Numerous functional abnormalities in organs that receive an autonomic innervation occur in patients with long standing diabetes (table 4). Many of these defects have no clinical manifestations and, alone, do not adversely affect prognosis. None the less, the symptoms of autonomic neuropathy can be extremely disagreeable, and disabling if several occur together. Gustatory sweating is the most common, followed by orthostatic hypotension and diarrhoea. Impotence is relatively common in diabetic men and is a feature of autonomic neuropathy, although psychogenic and vascular factors contribute in many cases. Bladder hypotonia and gastroparesis severe enough to cause symptoms are rare.

Autonomic neuropathy was previously thought to impair awareness of hypoglycaemia. This notion has now been refuted, although some neuroendocrine responses to hypoglycaemia are blunted in patients with neuropathy.

Many problems of autonomic neuropathy are due to sympathetic denervation of vascular smooth muscle in different tissues and organs. Some of these problems, together with their functional and clinical consequences, are considered next.

BLOOD VESSELS AND BLOOD FLOW

Sympathetic denervation of blood vessels causes structural and functional changes in arterial smooth muscle. Degenerative changes lead to calcification and even ossification and thus to stiffening of the arteries. ${ }^{47}$ The cause of these changes is unknown, but there is early evidence in diabetic arteries for expression of mRNA for Gla protein and osteopontin which may promote calcification. Whether neuropathy is the cause of the molecular changes is unknown. Calcification is also known to occur in the smooth muscle of the vas deferens in long term diabetes; this tissue has a rich sympathetic innervation and degenerative changes might be due to similar processes to those in the arteries.

Peripheral vascular sympathetic denervation $^{48}$ causes peripheral vasodilatation associated with the opening of arteriovenous shunts. A substantial increase in blood flow results, which is on average five times higher in neuropathic patients than in controls, and can even be demonstrated without clinical evidence of neuropathy. Some of the clinical features of the neuropathic foot are explained by these changes in blood flow; the feet are excessively warm, have bounding pulses and marked venous distension, and the venous $\mathrm{PO}_{2}$ is increased as a result of the excessive arteriovenous shunting. Neuropathic oedema results from these haemodynamic changes and is occasionally severe. Bone blood flow is raised in these patients and, as already discussed, may 
in turn contribute to the osteopenia which predisposes to the development of Charcot's neuroarthropathy.

Blood flow responsiveness to various stimuli is also abnormal. The best known is the reduction of peripheral vasoconstriction in response to sympathetic stimuli either on coughing or standing up - the latter in part responsible for orthostatic hypotension. Paradoxical responses also occur-notably, the vasoconstrictor response which takes place on heating rather than the expected vasodilatation, ${ }^{49}$ and the vascular effects of insulin which lead to a reduction rather than an increase of peripheral vascular resistance and may be the mechanism by which insulin exacerbates orthostatic hypotension. ${ }^{50}$

These findings on structural and functional changes of the peripheral vasculature in diabetic neuropathy have resulted in at least one new treatment-namely, the use of ephedrine (a sympathomimetic stimulant) to alleviate neuropathic oedema. ${ }^{30}$ The effects can be dramatic; dosage starts at $30 \mathrm{mg}$ three times a day increasing to a maximum of $60 \mathrm{mg}$ three times a day. It can be used for this purpose indefinitely without tachyphylaxis.

\section{ORTHOSTATIC HYPOTENSION}

The most serious clinical consequence of vascular denervation is orthostatic hypotension. It is due to diminished peripheral vasoconstriction and some failure of splanchnic blood flow reduction on standing, but these defects are not as marked as would be expected even in severe cases. Noradrenaline concentrations are normally reduced in these patients, whereas renin responses may or may not be abnormal.

Measured orthostatic hypotension, defined as a decrease of systolic blood pressure on standing of more than $30 \mathrm{~mm} \mathrm{Hg}$, is not uncommon in diabetic neuropathy although symptoms are rare. Patients may then complain at the least of mild giddiness and at most may be disabled by the condition, unable to stand for more than a few minutes at a time, although this state is very rare. Symptoms range from mild giddiness or muzzy headedness on standing up, progressing to a grey mistiness of vision followed by a curious pain in the back of the neck and shoulders in a "coat hanger" distribution $^{51}$ and later unconsciousness. Distortion of vision can occur. Symptoms are often worse on rising from bed in the morning, but they vary substantially both through the day and from week to week, ranging from negligible to severe. They do not show very close correlation with actual fall of blood pressure although when the systolic pressure is less than $70 \mathrm{~mm}$ $\mathrm{Hg}$ few patients can remain upright. Orthostatic hypotension is exacerbated by insulin administration, ${ }^{50}$ and just occasionally episodes of loss of consciousness from insulin induced orthostatic hypotension are confused with those from hypoglycaemia. Orthostatic hypotension can persist over many years and apart from the rare patients who develop disabling disease it often fails to progress even during 10-15 years. It never remits completely.
Treatment is needed when symptoms become troublesome. Firstly, drugs which exacerbate hypotension-notably, diuretics, tranquilisers, and antidepressants - should be stopped. Raising the head of the bed using 9 inch $(23 \mathrm{~cm})$ blocks, and full length elastic stockings can help. Measures which increase blood volume are the most valuable and include a high salt intake and the use of fludrocortisone to a maximum of 0.4 mg-0.6 mg daily; sometimes the oedema which results is unacceptable. Sympathomimetic agents may have a limited effect, especially midodrine which is an adrenergic agonist (available in the United Kingdom on a named patient basis). Non-steroidal anti-inflammatory drugs and ephedrine may help; pindolol, ergotamine, octreotide, clonidine, and metoclopramide have theoretical advantages but are not clinically useful.

The survival of patients with orthostatic hypotension is worse than for those with other autonomic symptoms alone. The development of left ventricular hypertrophy may be the cause for the higher mortality from myocardial infarction. It is likely to be due to higher blood pressures during the night which result from the loss of the normal diurnal-nocturnal fluctuations of blood pressure described in patients with autonomic neuropathy.

SYMPATHETIC DENERVATION OF THE KIDNEY AND ERYTHROPOIETIN

Erythropoietin production is stimulated chiefly by hypoxia and anaemia and is impaired in renal failure and some other chronic diseases. The kidney receives a rich sympathetic innervation which modulates erythropoietin production. Experimental renal denervation leads to a reduced erythropoietin production in response to hypoxia and early reports on some patients with multisystem atrophy and a few diabetic patients have indicated erythropoietin depletion. $^{53}$

In a preliminary study of 15 patients with severe symptomatic autonomic neuropathy, including postural hypotension but without renal failure, examined at King's College Hospital, 10 were found to be anaemic (mean haemoglobin 10.9 (SD 0.2) g/dl), occasionally considerably so, and several had haemoglobin values below $10 \mathrm{~g} / \mathrm{dl}$ without other causes for their anaemia. Serum erythropoietin concentrations for these anaemic neuropathic patients were much lower than expected. It seems that diabetic autonomic neuropathy can cause anaemia from erythropoietin deficiency. Preliminary studies have shown that the anaemia responds rapidly to erythropoietin treatment although its effect in improving orthostatic hypotension still requires evaluation.

\section{GASTROPARESIS}

Vomiting from gastroparesis is a rare complication of autonomic neuropathy. ${ }^{54}$ It is usually intermittent, and only rarely so persistent that surgical measures may be needed. Gastroparesis is characterised by a gastric splash and radiologically by large food residues, absent peristalsis, a failure to empty the stomach, and a patulous pylorus. 
The cause of gastroparesis is uncertain..$^{55}$ It is usually attributed to denervation and there is evidence (although not consistent) for fibre loss in the vagus nerve. ${ }^{56}$ Denervation of gut smooth muscle normally causes muscular hypertrophy, yet our own findings on specimens taken from patients with gastroparesis undergoing gastrectomy show that the opposite has occurred; there is evidence of smooth muscle atrophy and degeneration in the muscularis propria with fibrosis between muscle bundles similar to that seen in known cases of gut myopathy. Distinctive " $M$ " bodies have also been found in smooth muscle cells: these appear as intracellular round eosinophilic bodies and are probably a degenerative phenomenon. ${ }^{57}$ Gastroparesis may, at least in some cases, be due to gastromyopathy.

Treatment of vomiting from gastroparesis is difficult to evaluate because symptoms are usually intermittent. Dopamine antagonists (metoclopramide and domperidone) enhance gastric tone and emptying. ${ }^{58}$ They may accelerate gastric emptying in diabetic autonomic neuropathy with some effect. The motility stimulant cisapride can also be tried. These drugs form the mainstay of treatment during vomiting bouts. The use of erythromycin has been described recently; this binds to motilin receptors and acts as a motilin agonist. ${ }^{59}$ Intravenous erythromycin causes a substantial acceleration of gastric emptying; oral administration is less effective and whether or not it is a useful approach is still uncertain.

Persistent and intractable vomiting from gastroparesis is very rare. Endoscopic insertion of a gastrostomy or jejunostomy tube for self feeding is now possible and of value and if symptoms remit the tube is simply withdrawn. In patients in whom total gastric stasis can be proved, and vomiting is truly persistent and intolerable, definitive surgery can help. A two thirds gastrectomy with a low Roux-en-Y loop $60 \mathrm{~cm}$ beyond the anastomosis has had considerable success in four of our patients with this rare condition ( $\mathrm{N}$ Ejskjaer et al, unpublished observations). This approach seems more successful than the more limited surgery performed in the past.

DIABETIC DIARRHOEA

Diabetic diarrhoea is a very disagreeable symptom of autonomic neuropathy. Borborygmi and discomfort precede attacks of watery diarrhoea, without pain or bleeding, and usually without evidence of malabsorption. Faecal incontinence is common, especially at night, when exacerbations seem to be worse. Symptoms last from a few hours to a few days and then remit, with normal bowel action or even constipation (sometimes induced by treatment) between attacks. Intermittent attacks of diabetic diarrhoea tend to persist over many years and rarely remit completely. Very occasional patients have almost continuous diarrhoea for which no other cause is discovered, and they are extremely difficult to treat.

The underlying cause of diabetic diarrhoea is not established. Gut denervation probably alters gut motility and bacterial overgrowth has been found in these cases, yet many other mechanisms are possible and have not been well studied. ${ }^{60}$

Full investigation of diarrhoea in a diabetic patient is crucial so as not to overlook easily treatable causes such as coeliac disease, the frequency of which may be increased in type 1 diabetes, pancreatic malabsorption, or other rarer causes. Normal autonomic function tests virtually exclude visceral neuropathy as a cause. Nevertheless, the presence of abnormal autonomic function is not in itself sufficient to establish a diagnosis of diabetic diarrhoea and may thus be very deceptive. The diagnosis is most likely to be correct in long standing type 1 patients with other autonomic symptoms such as gustatory sweating and orthostatic hypotension.

Tetracycline offers effective treatment in about half of the patients, and is given in one or two doses of $250 \mathrm{mg}$ at the onset of an attack which is abruptly aborted. If this fails, a range of antidiarrhoea remedies can be triednotably, codeine phosphate, lomotil, or loperamide (Imodium). Clonidine has also been proposed. The use of somatostatin as its analogue octeotride has been suggested: its general gut antisecretory effect is effective in the watery diarrhoea of the VIPoma syndrome and it may help to alleviate the symptoms of diabetic diarrhoea although further investigation is needed.

\section{OESOPHAGUS}

Abnormal oesophageal motility has been described in diabetic autonomic neuropathy. No symptoms have been attributed to this functional abnormality.

\section{GaLl BLADDER}

Enlargement of the gall bladder, probably due to poor contraction, may be a feature of diabetes related to autonomic neuropathy. Studies by ultrasonography have not confirmed enlargement of the gall bladder, but do suggest impaired muscular contraction. ${ }^{61}$ There are no known clinical effects from this. Administration of erythromycin, however, enhances gall bladder emptying.

DIABETIC CYSTOPATHY ${ }^{62}$

Autonomic neuropathy affecting the sacral nerves causes bladder dysfunction. Bladder function tests are commonly abnormal in diabetic patients with neuropathy but symptoms are relatively rare, usually occurring in those who already have advanced complications. Most men with a neurogenic bladder are also impotent.

Impairment of bladder function is chiefly the result of neurogenic detrusor muscle abnormality, while pudendal innervation of perineal and periurethral striated muscle is usually unaffected in diabetic neuropathy. Afferent damage results in impaired sensation of bladder filling, and leads to detrusor areflexia; thus the bladder pressure during cystometrography fails to increase as the bladder is filled. In advanced cases, bladder emptying is reduced because of impaired detrusor activity and possibly failure of the internal sphincter to open adequately. 
Measurements of urinary flow show that the peak flow rate is reduced and that duration of flow is increased.

There are no symptoms in the early stages, but later patients experience hesitancy during micturition, develop the need to strain, a feeble stream, and a tendency to dribble. Micturition sometimes occurs in short interrupted spurts as the result of straining. Patients may be aware of lengthening intervals between micturition, and also experience a sensation of inadequate bladder emptying. Gradually, residual urine volume increases and, in severe cases, gross bladder retention occurs with abdominal swelling and sometimes overflow incontinence as well. Bladder capacity may exceed one litre.

The diagnosis of a neurogenic bladder is likely to be made in patients with clinical evidence of severe neuropathy. It is, however, important to exclude bladder neck obstruction and, especially, prostatic obstruction in men as a cause of the patient's symptoms. Ultrasound examination before and after emptying should be performed, and cystoscopy is usually needed; rarely, diabetic neurogenic bladder causes hydroureter and hydronephrosis. Occasionally, more complex bladder function tests are needed. These include cystograms, cystometrography, and urinary flow rate measurements.

The principles of treatment are to compensate for deficient bladder sensation and thus prevent the development of a high residual urinary volume. For those diabetic patients who have few symptoms of cystopathy, education is important and may suffice. In particular, the patients should be told to void every three hours during the daytime. With more severe symptoms, more active measures are needed. Prazosin, an $\alpha 1$-adrenoreceptor blocker, may help by reducing urethral resistance. Self catheterisation three times daily is now the recommended treatment for patients with chronic retention. Recurrent urinary tract infections are often troublesome in these patients, and protracted courses of antibiotics, changing monthly, may be needed to prevent this problem.

IMPOTENCE ${ }^{63}$

Autonomic neuropathy is still considered to be the main aetiological factor in diabetic impotence. It is due to erectile failure resulting from damage both to the parasympathetic and sympathetic innervation of the corpora cavernosa. VIPergic nerves are also important in the vasodilatation of erection and the concentration of VIP (vasoactive intestinal peptide) is low in the penile corpora in diabetic patients with autonomic neuropathy. Failure to achieve erection may also be the result of a concomitant sensory deficit in the dorsal nerve of the penis. Impotence may also be due to vascular occlusion of the branches of the internal pudenal artery. In rare cases, erectile failure may be caused by the Leriche syndrome. The onset of neuropathic impotence is usually gradual, progressing slowly over months, but complete erectile failure is usually present within two years of the onset of symptoms. This history contrasts with psychogenic impotence which begins suddenly and in which nocturnal erections are maintained.

The diagnosis of neuropathic impotence in diabetes is difficult. The use of an intracavernosal injection of prostaglandin $\mathrm{E}_{1}$ (Caverject, alprostadil) is to some extent useful in distinguishing neurogenic from vasculogenic impotence-it causes an erection in the first and fails to do so in the second. This is helpful both in terms of diagnosis and giving guidance in the choice of treatment. Autonomic function tests give some guidance as to the presence of autonomic neuropathy, but they do not establish conclusively in a patient whether it is the cause of impotence.

The rational treatment of diabetic impotence depends on a careful history, in particular to evaluate any psychological component. If this factor is present, then the patient and his partner may be helped by appropriate discussion and advice. For younger patients, rigid penile implants are often successful, especially since ejaculation is often retained. Inflatable prostheses can also be inserted, but are more prone to failure. The intracavernous injection of the vasodilator prostaglandin $\mathrm{E}_{1}$ causes an erection in patients without severe vascular disease, and offers a treatment which some men find satisfactory; potential problems exist from infection and penile fibrosis and this treatment should only be provided under expert supervision. The use of a vacuum pump applied to a condom is less invasive, and is a technique which some patients find satisfactory, especially if they are properly instructed. In vasculogenic impotence, arterial disease is often distal and arterial reconstruction is only likely to be useful in those patients with major arterial occlusions.

New treatments using intraurethral prostaglandins, or oral treatment with sildenafil, a selective inhibitor of type 5 cyclic GMPspecific phosphodiesterase, are under active investigation.

\section{RESPIRATORY RESPONSES AND ARREST}

Sudden respiratory arrests have been described in diabetic patients with autonomic neuropathy. In most of these episodes, there was some interference with respiration either by anaesthesia or drugs, or bronchopneumonia. These episodes are transient, and although temporary assisted ventilation may be needed, recovery to normal health is expected. Anaesthetists need to be forewarned of this possibility when patients with symptomatic autonomic neuropathy require even minor surgery. Whether respiratory arrest is responsible for the sudden unexplained deaths reported in diabetic patients with autonomic neuropathy is unclear, ${ }^{64}{ }^{65}$ but we suspect, from clinical observation, that it might be.

\section{SWEATING ABNORMALITIES}

Defective sweating in diabetic neuropathy was initially described many years ago. ${ }^{66-68}$ The sweat gland is an important structure with a complex peptidergic as well as cholinergic innervation. Neuropeptide immunoreactivity, especially for VIP, is low in diabetic sudomotor 
nerves. There is a renewed interest in sweating dysfunction in diabetic neuropathy, brought about by the development of new techniques. Measurement of sweating in the periphery is one of the few quantitative methods for assessing cholinergic nerve function, although the tests are complex and require special apparatus.

The most common sweating deficit is in the feet in a classic stocking distribution. There is a close correlation with other autonomic defects, especially with orthostatic hypotension, but also with cardiac vagal denervation, although the cardiovascular function tests tend to be abnormal before there is evidence of peripheral sweating loss. Abnormal responses may be found in cases of painful neuropathy, and patients with truncal mononeuropathies may have patchy sweating defects. These tests all confirm the widespread damage to small nerve fibres which occurs in diabetic neuropathy.

Gustatory sweating is a highly characteristic symptom of diabetic autonomic neuropathy, ${ }^{67} 68$ occurring more commonly than previously thought, and seen even more often in those patients who have nephropathy. Sweating begins after starting to chew tasty food, especially cheese. It starts on the forehead, and spreads to involve the face, scalp, and neck and sometimes the shoulders and upper part of the chest, compelling patients to keep a towel at the dinner table. The distribution of the sweating is in the territory of the superior cervical ganglion. It may be of sudden onset; its cause is unknown, although aberrant nerve fibre regeneration has been suggested. Gustatory sweating, once established, generally persists over many years, although there can be a remarkable and unexplained remission after renal transplantation.

Gustatory sweating is occasionally sufficiently severe to need treatment; anticholinergic drugs are highly effective although side effects may limit their use. Propantheline bromide (Pro-Banthine) can be used. It is given half an hour before meals, but may also be effective if given before single meals at social occasions. Clonidine may help. Recently, the use of glycopyrrolate cream (Robinul) has been described. The cream is made from glycopyrrolate powder (an antimuscarinic anticholinergic agent) combined with a standard cream base (cetamacrogol A), in an $0.5 \%$ concentration, although concentrations of $1.0 \%$ or $2.0 \%$ may be more effective. The cream is applied to the affected areas, avoiding contact with the mouth, nose, and eyes. The area should not be washed for four hours after the application. The only contraindication known is narrow angle glaucoma which may be exacerbated if the eye is accidently contaminated.

PROGNOSIS

Autonomic function declines with age, but in diabetes it deteriorates, on average, faster than in normal subjects. Thus variation in heart rate which normally decreases at about 1 beat $/ \mathrm{min}$ every 3 years declines about three times faster in diabetic patients, although there is substantial variation. ${ }^{69}$ Most patients who develop abnormal autonomic function do not become symptomatic. Mortality of asymptomatic patients with autonomic dysfunction may be increased but the prognosis is generally good, and $90 \%$ of our patients (all under 50 years old at the beginning of the study) were alive 10 years later. By contrast, the outcome for those with symptomatic autonomic neuropathy is not as good, although even in this group, $73 \%$ were still alive after a decade. Ewing et $a l^{70}$ reported a poorer prognosis, although patient selection was different: the patients were older and some had renal damage. Those with orthostatic hypotension seem to have the highest mortality, perhaps because of the premature development of left ventricular hypertrophy. Most deaths in these patients are from renal failure or myocardial infarction. There are a few sudden unexplained deaths among patients with autonomic neuropathy, which might be due to respiratory arrest rather than cardiac arrest or arrhythmia.

Established symptoms of autonomic neuropathy, including diarrhoea, vomiting from gastroparesis and postural hypotension run a very protracted although intermittent course and rarely become disabling, even over a 10 to 15 year period. ${ }^{69}$ Postural hypotension fluctuates substantially with a corresponding variation in the intensity of symptoms. Gustatory sweating also tends to persist without remission, although many patients describe disappearance of this symptom after renal transplantation. The general absence of progression to debilitating disease remains unexplained and contrasts with devastating and, indeed, often fatal progression of the primary autonomic failure. Malins made many of these observations some years ago and wrote that "The prognosis for autonomic manifestations is poor although the disability is often surprisingly slight." $^{71}$

FOCAL AND MULTIFOCAL NEUROPATHIES

Focal peripheral nerve lesions are commoner in patients with diabetes than in the general population. They result from various causes. There is evidence that isolated third cranial nerve lesions have an ischaemic basis but they are unusual for ischaemic lesions in that they are demyelinating in nature rather than involving axonal destruction. ${ }^{72}$ The pathological basis may be reperfusion injury which has been shown experimentally to cause demyelination in peripheral nerve. ${ }^{73}$ The favourable prognosis of diabetic third cranial nerve lesions is explicable in terms of recovery by remyelination. ${ }^{72}$

Diabetic nerve shows increased susceptibility to compression injury so that entrapment neuropathies and focal lesions from external compression occur more frequently than in the general population. The reason for the increased susceptibility is not known.

DIABETIC TRUNCAL RADICULONEUROPATHY This manifestation of diabetes often gives rise to diagnostic difficulty, the symptoms suggesting spinal nerve root compression. Radicular pain, focal truncal sensory loss, and cutaneous hyperaesthesia ${ }^{74}$ and focal weakness of the 
muscles of the anterior abdominal wall ${ }^{75-77}$ are the manifestations. The symptoms can be unilateral or bilateral and can involve several adjacent dermatomes or the territories of adjoining intercostal nerves. ${ }^{74}$ Spontaneous recovery usually occurs within 3 to 6 months.

PROXIMAL DIABETIC NEUROPATHY

This not entirely satisfactory label is used to describe cases of unilateral or commonly asymmetric bilateral lower limb motor neuropathy (diabetic amyotrophy). Distal lower limb muscles may also be affected. Radicular sensory loss may be present ${ }^{78}$ and which in some cases is prominent. ${ }^{79}$ The onset is most often subacute but it may be insidious. Pain, particularly at night, can be a troublesome feature. Truncal radiculoneuropathy may coexist and occasionally the upper limbs are affected. ${ }^{80}$ Spontaneous recovery is frequent, ${ }^{81}$ although not all patients recover fully. ${ }^{82}$

It has recently been shown that in about a third of patients with proximal diabetic neuropathy, inflammatory changes, sometimes vasculitic, are evident on nerve biopsy ${ }^{78}$ so that treatment with corticosteroids, or by immunosuppressive or immunomodulatory measures, might be considered in cases that fail to resolve spontaneously. Results of controlled treatment trials are not available.

\section{SUPERIMPOSED CHRONIC INFLAMMATORY}

DEMYELINATING POLYNEUROPATHY (CIDP)

There is evidence that, as for hereditary motor and sensory neuropathy, CIDP may be superimposed on diabetic neuropathy as a secondary immunological event. ${ }^{83} 84$ Prominent motor involvement or a reduction of nerve conduction velocity into the demyelinating range would suggest this possibility. Confirmation may be obtained by the finding of oligoclonal IgG bands in the CSF or inflammatory infiltrates on nerve biopsy. Treatment options are as for isolated CIDP.

\section{Cerebrovascular disease}

Large population studies have shown that strokes are more frequent and have a higher mortality in patients with diabetes. ${ }^{85}$ These studies have disclosed an increase in the relative risk in the female as compared with the diabetic male population. Thus in a study in Sweden, the highest rise was 6-fold in diabetic males but 13-fold in diabetic females. ${ }^{86}$ The greatest rise is in the 5th and 6th decades, decreasing significantly at later ages. ${ }^{87}$ Previously undetected diabetes is a recognised feature in patients with ischaemic strokes. ${ }^{87} 88$

The association of stroke due to cerebral infarction is less closely related to internal carotid disease than in the non-diabetic population. ${ }^{89}$ Postmortem studies ${ }^{90}$ have shown that most ischaemic strokes are the result of lacunar infarcts related to occlusion of small paramedian perforating arteries. The main source of thromboembolic strokes in diabetic patients is the internal carotid artery. ${ }^{91}$ In one study, the frequency of cardioembolic strokes was higher after myocardial infarction in diabetic than in non-diabetic patients, ${ }^{92}$ although Palumbo et $a l^{93}$ found that coronary artery disease was not associated with an increased frequency of strokes in their population based study of diabetic patients.

The frequency of transient ischaemic attacks is also increased in diabetic patients, but the average age of onset does not differ from a non-diabetic population. ${ }^{93}$

Hypertension is the main risk factor for strokes in diabetic patients ${ }^{94}$ and this also applies to transient ischaemic attacks. ${ }^{93}$ Treatment of hypertension found at the time of diagnosis of diabetes reduces the subsequent risk both of strokes and transient ischaemic attacks. ${ }^{93}$ Obesity, cigarette smoking, hyperlipidaemia, and glycaemic control have not been found to be independent risk factors for strokes..$^{93}{ }^{94}$ The effect of antiplatelet therapy on stroke prevention has not been examined extensively. The American Veterans' Administration Cooperative Study ${ }^{95}$ followed up diabetic veterans with recent gangrene and amputation. The incidence of stroke and transient ischaemic attacks was less in the group treated with a combination of aspirin and dipyramidole. This finding is in accord with the fact that platelet adhesiveness is increased in diabetic patients. ${ }^{96}$ In the European Stroke Prevention Study, ${ }^{97}$ however, treatment with this combination failed to produce any detectable reduction in the occurrence of strokes, although the number of diabetics included in the study was small.

The prevalence of cerebral haemorrhage and subarachnoid haemorrhage has been reported to be the same or less in diabetic than in nondiabetic patients. ${ }^{90} 98$

\section{Infections}

Diabetic patients probably have an increased susceptibility to infection, related in part to compromised phagocytic function. ${ }^{99}$ In diabetic patients with unexplained acute or subacute cerebral or spinal cord symptomatology, the possibility of meningitis or cerebral or epidural abscess should be considered. Thus in a series of 43 cases of bacterial spinal epidural abscesses reported by Darouiche et al, ${ }^{100}$ eight had diabetes, representing the single most frequent predisposing cause. This was even more evident in the series of 41 patients documented by Khanna et $a l^{101}$ of whom $22(53.7 \%)$ had diabetes. Enterococcal meningitis may develop in ketoacidotic patients, usually related to septicaemia from Enterococcus faecalis, which is a normal commensal organism in the gut. Diagnosis can be difficult as signs of meningism may be lacking. Two examples of infections that may affect the nervous system are particularly characteristic of diabetes: mucormycosis, and malignant external otitis.

Rhinocerebral mucormycosis (invasive zygomycosis) $)^{102}$ is caused by zygomycete mucor-like fungi which are common airborne moulds that grow on decaying vegetable matter. ${ }^{102}$ Diabetic ketoacidosis is a predisposing condition for infection when the fungus invades the paranasal sinuses. The patients are febrile and present with facial pain, swelling, nasal obstruction, 
and proptosis. The fungi tend to invade blood vessels, leading to thrombosis. Involvement of the orbit may lead to blindness and intracranial extension to invasion of the brain. ${ }^{103}$ The diagnosis is best made histologically on biopsy specimens. This is a serious condition with a high mortality. Treatment is by surgical debridement together with intravenous and sometimes local instillation of amphotericin B.

Malignant external otitis is also a serious infection, ${ }^{104}{ }^{105}$ usually encountered in poorly controlled diabetic patients who develop otalgia. Infection is usually with Pseudomonas aeruginosa and can follow syringing of the external auditory meatus. Mastoiditis and intracranial extension may occur leading to multiple cranial nerve palsies, sinus thrombosis, or meningitis. Treatment is with antipseudomonal agents together with surgical intervention if required.

\section{Congenital malformations of the nervous system}

Congenital malformations occur in 3\%-8\% of all births to diabetic women, representing a 2-4-fold increase over non-diabetic mothers. ${ }^{106-108}$ In the series from Birmingham, United Kingdom reported by Soler et al, ${ }^{106}$ $2.1 \%$ had neurological abnormalities compared with an expected rate of $0.65 \%$. The malformations included anencephaly, microcephaly, hydrocephalus, encephalocele, cerebral diplegia, Dandy-Walker syndrome, Arnold-Chiari malformation, spina bifida, and sacral agenesis. Anencephaly and spina bifida were the commonest, occurring in $0.57 \%$ (a 3-fold increase) and $0.56 \%$ (a 2-fold increase) respectively. Milunsky et $a l^{109}$ found neural tube abnormalities in 19.5/1000 children of diabetic women compared with $1-2 / 1000$ in the general population. The caudal regression syndrome (sacral agenesis, phocomelic diabetic embryopathy), ${ }^{110}$ although rare, is particularly associated with maternal diabetes, occurring in $0.2 \%-0.5 \%$ of pregnancies, representing a 200 -fold increase over the rate in the general population. ${ }^{111}$ It is probably the result of a defect in the midposterior axis mesoderm of the embryo before the fourth week of gestation, leading to absence or hypoplasia of caudal structures.

The precise mechanism of diabetic embryopathy is not established. Hyperglycaemia may act to produce a teratogenic insult in early pregnancy. Insulin does not appear to be directly teratogenic. Genetic factors may be important. In an experimental study on teratogenesis in diabetic rats, the rate of malformations differed markedly between strains of rat. ${ }^{112}$ Congenital malformations in infants of diabetic mothers can be prevented if tight control of diabetes is established before conception: to achieve this for most diabetic women sound arrangements for prepregnancy counselling need to be established. ${ }^{113}$

\section{Summary}

Diabetes mellitus is subdivisible into type 1 insulin dependent and type 2 non-insulin dependent forms. It may be encountered in genetic syndromes that include neurological involvement, the most common of which are mitochondial disorders, Friedreich's ataxia, and the Wolfram syndrome. Diabetes is responsible for a wide range of neurological manifestations. These can be the direct result of the metabolic disorder or its treatment, or they can represent secondary manifestations. Conditions that result directly from the diabetic state can reflect acute metabolic decompensation, as in diabetic ketoacidosis encountered in type 1 cases and in which diffuse cerebral oedema, especially frequent in children, is an important complication. Hyperosmolar non-ketotic coma is usually seen in type 2 cases. The salient consequences of hypoglycaemia, found as a complication of treatment with insulin or sulphonylurea drugs, are neurological. Late secondary manifestations are a major problem in diabetes. As they affect the nervous system, the most important are peripheral neuropathy and cerebrovascular disease. There is no single diabetic neuropathy but a range of syndromes of which a distal predominant sensory polyneuropathy is frequent. Sensory polyneuropathy the most important risk factor for chronic foot ulceration. Severe autonomic neuropathy is uncommon and is usually encountered in type 1 cases. Focal and multifocal neuropathies comprise isolated cranial and limb neuropathies, truncal radiculoneuropathies and proximal lower limb neuropathy (diabetic amyotrophy). Some of the focal neuropathies are the consequence of an abnormal susceptibility of diabetic nerve to external compression or entrapment. Both transient ischaemic attacks and stroke are commoner in diabetic patients than in nondiabetic subjects, reflecting the increased risk of macrovascular disease in diabetes. Infections are probably more common in diabetic patients but certain types, in particular rhinocerebral mucormycosis and malignant external otitis, are especially characteristic. Finally, congenital malformations, including those affecting the nervous system, are more common in diabetic pregnancies, anencephaly and spina bifida being the most frequent.

1 American Diabetes Association. Report of the Expert Commitee on the Diagnosis and Classification of Diabetes Mellitus. Diabetes Care 1997;20:1183-96.

2 Van der Ouweland JM, Lemkes HH, Gerbitz KD, et al. Maternally inherited diabetes and deafness (MIDD): a distinct subtype of diabetes associated with a mitochondrial RNA $^{\text {Leu(UUR })}$ gene point mutation. Muscle Nerve 1995;3: S124-30.

3 Hanna MG, Nelson I, Sweeney MG, et al. Congenital encephalomyopathy and adult onset myopathy and diabetes mellitus: different phenotypic associations of a new heteroplasmic mtDNA tRNA glutamic acid mutation. Am $\mathcal{F}$ Hum Genet 1995;56:1026-33.

4 Wather M, Turnbull DM. Mitochondrial related diabetes: a Wather M, Turnbull DM. Mitochondrial related diab
clinical perspective. Diabet Med 1997;14:1007-9.

5 Susuki Y, Kadowaki H, Katagiri H, et al. Post-treatment neuropathy in diabetic subjects with mitochondrial mRNA (Leu) mutation. Diabetes Care 1994;17:777-8.

6 Campuzano V, Montermini L, Molto MD, et al. Friedreich's ataxia: autosomal recessive disease caused by an intronic GAA triplet repeat expansion. Science 1996;217:1423-7.

7 Priller J, Scherzer CR, Faber PW, et al. Frataxin gene of Friedreich's ataxia is targeted to mitochondria. Ann Neurol 1997;42:265-9.

8 Wilson RB, Roof DM. Respiratory deficiency due to loss of mitochondrial DNA in yeast lacking the frataxin homologue. Nat Genet 1997;16:352-7.

Harding AE. The hereditary ataxias and related disorders. Edinburgh: Churchill Livingstone, 1984.

10 Page MMJ, Asmal AC, Edwards CRW. Recessive inheritance of diabetes: the syndrome of diabetes insipidus, diabetes mellitus, optic atrophy, and deafness. $Q \mathcal{F}$ Med diabetes mellitus,

11 Durr JA, Hoffman WH, Sklar AH, et al. Correlates of brain edema in uncontrolled IDDM. Diabetes 1992;41:627-32. 
12 Frier B, Fisher M, eds. Hyperglycaemia and diabetes. Clinical and physiological aspects. London: Edward Arnold, 1993.

13 Newrick PG, Wilson AJ, Jakubowski J, et al. Sural nerve oxygen tension in diabetes. BMf 1986;293:1053-4.

14 Schneider U, Quasthoff S, Mitrovic N, et al. Hyperglycaemic hypoxia alters after-potential and fast $\mathrm{K}^{+}$conductance of rat axons by cytoplasmic acidification. $\mathcal{F}$ Physio 1993;465:697-703.

15 Gregersen G. Variations in motor conduction velocity produced by acute changes in the metabolic state in diabetic patients. Diabetologia 1968;4:273-7.

16 Ward JD, Barnes CG, Fisher DJ, et al. Improvement in nerve conduction velocity following treatment in newly diagnosed diabetics. Lancet 1971;i:428-31.

17 Steiness IB. Vibratory perception in diabetics during arrested blood flow to the limb. Acta Med Scand 1959;163 195-205.

18 Schneider U, Niedermeier W, Grafe P. The paradox between resistance to hypoxia and liability to hypoxic damage in hyperglycemic peripheral nerves. Evidence for glycolysis involvement. Diabetes 1993;42:981-7.

19 Dyck PJ, Kratz KM, Karnes JL, et al. The prevalence by staged severity of various types of diabetic neuropathy, retinopathy, and nephropathy in a population-based retinopathy, and nephropathy in

20 Guy RJC, Clark CA, Malcolm PN, et al. Evaluation of thermal and vibration sensation in diabetic neuropathy. Diabetologia 1985;28:131-7.

21 Dyck PJ, Karnes KL, Daube J, et al. Clinical and neuropathological criteria for the diagnosis and staging of diabetic polyneuropathy. Brain 1985;108:861-80.

22 Dyck PJ. Detection, characterization, and staging of polyneuropathy: assessed in diabetics. Muscle Nerve 1988; 11:21-2.

23 Dyck PJ, Karnes JL, O'Brien PC, et al. The Rochester neuropathy study. Reassessment of tests and criteria for diagnosis and staged severity. Neurology 1992:42:1164-70.

24 Feldman EL, Stevens MJ, Thomas PK, et al. A practical two-step quantitative clinical and electrophysiological assessment for the diagnosis and staging of diabetic neuropathy. Diabetes Care 1994;7:1281-9.25.

25 Watkins PJ. The natural history of the diabetic neuropathies. Qf Med 1990;77:1209-18.

26 Diabetes Control and Complications Trial Research Group. The effect of intensive treatment of diabetes on the development and progression of long-term complications in insulin-dependent diabetes mellitus. $N$ Engl $f \mathrm{Med}$ 1993;329:977-86.

27 Boulton AJM, Kubrusly DB, Bowker JH, et al. Impaired vibratory perception and diabetic foot ulceration. Diabe vibratory perception
Med 1986;3:335-7.

28 Young MJ, Manes C, Boulton AJM. Vibration perception threshold predicts foot ulceration. Diabet Med 1992; 9(suppl 2):542.

29 Boulton AJM, Hardisty CA, Betts RP, et al. Dynamic foot pressures and other studies as diagnostic and management aids in diabetic neuropathy Diabetes Care 1983;6:26-33.

30 Edmonds ME, Archer AG, Watkins PJ. Ephedrine: a new treatment for diabetic neuropathic oedema. Lancet 1983;i: 548.

31 Young MJ, Bready JL, Veves A, et al. The prediction of diabetic neuropathic foot ulceration using vibration perception thresholds: a prospective study. Diabetes Care 1994;17: 557-61.

32 Edmonds ME, Blundell MP, Morris ME, et al. Improved survival of the diabetic foot: the role of a specialized foo clinic. $Q \mathcal{F}$ Med 1986;60:763-72.

33 Stevens MJ, Edmonds ME, Foster AVM, et al. Selective neuropathy and preserved vascular responses in the diabetic Charcot foot. Diabetologia 1992;35:148-52.

34 Cundy TF, Edmunds ME, Watkins PJ. Osteopenia and metatarsal fractures in diabetic neuropathy. Diabet Med 1985;2:461-73.

35 Brewer AC, Allman RM. Pathogenesis of the neurotrophic joint: neurotraumatic $v$ neurovascular. Radiology 1981;139: joint: neuro 349 .

36 Clohisy DR, Thompson RC. Fractures associated with neuropathic arthropathy in adults who have juvenile onset diabetes. F Bone foint Surg 1988;70A:1192-9.

37 Sanders LJ, Frykberg RG. Diabetic neuropathic osteoarthropathy: the Charcot foot. In: Frykberg RG, ed. The high risk foot in diabetes. New York: Churchill Livingstone, 1991:227-38.

38 Selby PL, Young MJ, Boulton AJM. Bisphosphonates: a new treatment for diabetic Charcot neuroarthropathy. Diabet Med 1994;11:28-31.

39 Cavanagh PR, Young MJ, Adams DE, et al. Radiographic abnormalities in the feet of patients with diabetic abnormalities in the feet of patients
neuropathy. Diabetes Care 1994;17:201-9.

40 Archer AG, Watkins PJ, Thomas PK, et al. The natural history of acute painful diabetic neuropathy. $f$ Neurol Neurosurg Psychiatry 1983;46:491-9.

41 Castellanos F, Mascías J, Zabala JA, et al. Acute painful diabetic neuropathy following severe weight loss. Muscle Nerve 1996;19:363-7.

42 Steele JM, Young RJ, Lloyd GG, et al. Clinically apparent eating disorders in young diabetic women: associations with painful neuropathy and other complications. $B M \mathcal{F}$ with painful neur

43 Llewelyn JG, Thomas PK, Fonseca V, et al. Acute painful diabetic neuropathy precipitated by strict glycaemic control. Acta Neuropathol 1986;72:157-63.
44 Tesfaye S, Malik R, Harris N, et al. Arterio-venous shunting and proliferating new vessels in acute painful neuropathy of rapid glycaemic control. Diabetologia 1996;39:329-35.

45 Guy RJC, Richards F, Edmonds MF, et al. Diabetic autonomic neuropathy and iritis: an association suggesting an immunological cause. BMF 1984;298:343-5.

46 Duchen LW, Anjorin A, Watkins PJ, et al. Pathology of autonomic neuropathy in diabetes. Ann Int $\mathrm{Med}$ 1980;92:301-3.

47 Edmonds ME, Morrison N, Laws JW, et al. Medial calcification and diabetic neuropathy. BMF 1982;284:92830.

48 Flynn MD, Tooke JE. Diabetic neuropathy and the microcirculation. Diabet Med 1995;12:298-301.

49 Stevens MJ, Edmonds ME, Douglas SLE, et al. Influence of neuropathy on the microvascular response to local heating in the human diabetic foot. Clin Sci 1991:80:249-56.

50 Porcellati F, Fanelli C, Bottini P, et al. Mechanisms of arterial hypotension after therapeutic dose of subcutaneous insulin in diabetic autonomic neuropathy. Diabetes 1993; 42:1055-64.

51 Mathias CJ, Bleasdale-Barr K, Smith G, et al. Intermittent muscle ache, particularly in the suboccipital/paracervical (coathanger) region in autonomic failure: frequency in associated neurological conditions and relationship to postural hypotension. F Neurol 1994;214(suppl 1):S85.

52 Purewal TS, Watkins PJ. Postural hypotension in diabetic autonomic neuropathy: a review. Diabet Med 1995;12:192200.

53 Hoeldtke RD, Streeton DH. Treatment of orthostatic hypotension with erythropoietin. N Engl F Med 1993;329:611-5.

54 Dowling CJ, Kumar S, Boulton AJM, et al Severe gastroparesis diabeticorum in a young patient

55 Horowitz M, Wishart JM, Jones KL, et al. Gastric emptying in diabetes: an overview. Diabet Med 1996;13:S16-22.

56 Guy RJC, Sharma AK, Thomas PK, et al. Gastroparesis diabeticorum: the role of surgery and the histological abnormalities of the vagus nerve. Diabetologia 1983;25: $160-7$.

57 Moscoso GJ, Driver M, Guy RJ. A form of necrobiosis and atrophy of smooth muscle in diabetic autonomic neuropathy. Pathol Res Pract 1996;181:188-94.

58 Horowitz M, Harding PE, Chatterton BE, et al. Acute and chronic effects of domperidone on gastric emptying in diabetic autonomic neuropathy. Dig Dis Sci 1995;30:1-9.

59 Peeters TL. Erythromycin and other macrolides as prokinetic agents. Gastroenterololgy 1993;105:1886-99.

60 Werth I, Myer-Wyss B, Spinas GA, et al. Non-invasive assessment of motility disorders in diabetic patients with and without cardiovascular signs of autonomic neuropathy. Gut 1992;33:1199-203.

61 Stone BG, Gavaler JS, Belle SH, et al. Impairment of gall bladder emptying in diabetes mellitus. Gastroenterology 1988;95:170-6

62 Fridmodt-Møller V. Diabetic cystopathy. A review of the urodynamic and clinical features of neurogenic bladder dysfunction in diabetes mellitus. Dan Med Bull 1978;25: $49-56$.

63 Alexander WD. Sexual function in diabetic men. In: Pickup JC, Williams G, eds. Textbook of diabetes, 2nd edition. Oxford: Blackwell Science, 1997:59.1-12.

64 Ewing DJ, Neilson JMM, Shapiro CM, et al. Twenty four hour heart rate variability. Effect of posture, sleep, and time of day in healthy controls and comparison with bedside tests of autonomic function in diabetic patients. Br Heart $\mathcal{F}$ 991;65:239-44.

65 Ewing DJ, Boland D, Neilson JMM, et al. Autonomic neuopathy, QT interval lengthening and unexpected deaths in male diabetic patients. Diabetologia 1991;34:182-5.

66 Bárány FR, Cooper EH. Pilomotor and sudomotor innervation in diabetes. Clin Sci 1956;15:533-40.

67 Watkins PJ, Facial sweating after food: a new sign of autonomic neuropathy. BMF 1973;i:83-7.

68 Stuart DD. Diabetic gustatory sweating. Ann Intern Med 1978;89:223-4.

69 Sampson MJ, Wilson S, Karagiannis P, et al. Progression of diabetic autonomic neuropathy over a decade in insulin dependent diabetics. $Q \mathcal{F}$ Med 1990;75:635-46.

70 Ewing DJ, Campbell IW, Clarke BF. The natural history of diabetic autonomic neuropathy. $Q \mathcal{F}$ Med 1980;193:95112.

71 Malins JM. Clinical diabetes mellitus. Margate: Eyre and Spottiswoode, 1968

72 Asbury AK, Aldredge H, Hershberg R, et al. Oculomotor palsy in diabetes mellitus: a clinico-pathological study. Brain 1970;93:555-66.

73 Nukada H, McMorran PD. Perivascular demyelination and intramyelinic oedema in reperfusion nerve injury. $\mathcal{F}$ Anat 1994;185:259-66.

74 Stewart JD. Diabetic truncal neuropathy: topography of the sensory defect. Ann Neurol 1989;25:233-8.

5 Boulton AJM, Angus E, Ayyar DR, et al. Diabetic thoracic polyradiculopathy presenting as an abdominal swelling. BMF 1984;289:798-800.

76 Parry GJ, Floberg J. Diabetic truncal neuropathy presenting as an abdominal hernia. Neurology 1989;39:1488-90.

77 Chaudhuri KP, Wren DR, Werring D, et al. Unilateral abdominal muscle herniation with pain: a distinctive variant of diabetic radiculopathy. Diabet Med 1997;14:803-7.

78 Llewelyn JG, Thomas PK, King RHM. Epineurial vasculitis in proximal diabetic neuropathy. $\mathcal{F}$ Neurol 1998;245:159in pr. 
79 Said G, Goulon-Goeau C, Lacroix C, et al. Nerve biopsy findings in different patterns of proximal diabetic neufindings in different patterns of proxir

80 Wilbourn AJ. Diabetic neuropathies. In: Brown WF, Bolton $\mathrm{CF}$, eds. Clinical electromyography, 2nd edition. Boston: Butterworth-Heinemann, 1993:477-516.

81 Coppack SW, Watkins PJ. The natural history of diabetic femoral neuropathy. $Q \mathcal{F}$ Med 1991;79:307-14.

82 Casey EB, Harrison MJG. Diabetic amyotrophy: a follow-up study. BMF 1972;i:656-9.

83 Cornblath DR, Drachman DB, Griffin JW. Demyelinating motor neuropathy in patients with diabetic polyneuropathy. Ann Neurol 1987;22:126-32.

84 Stewart JD, McKelvey R, Durcan L, et al. Chronic inflammatory demyelinating polyneuropathy (CIDP) in diabetics. 7 Neurol Sci 1996;142:59-64.

85 Bell DSH. Stroke in the diabetic patient. Diabetes Care 1994;17:213-9.

86 Lindegård $\mathrm{B}$, Hillbom $M$. Associations between brain infarction, diabetes, and alcoholism: observations from the infarction, diabetes, and alcoholism: observations from the 1987;75:195-200.

87 Gray CS, Taylor R, French JM, et al. The prognostic value of stress hyperglycaemia and previously unrecognized dia-

88 Lamk S, Ma JT, Wo E, et al. High prevalence of undiagnosed diabetes among Chinese patients with ischemic stroke. Diabetes Res Clin Pract 1991;14:133-7.

89 Alex M, Baron EK, Goldenberg S, et al. An autopsy study of cerebrovascular accident in diabetes mellitus. Circulation 1962;25:663-73.

90 Aronson SM. Intracranial vascular lesions in patients with diabetes mellitus. F Neuropathol Exp Neurol 1973;32:183-96.

91 Weinberger J, Biscarra V, Weisberg MK, et al. Factors contributing to stroke in patients with atherosclerotic disease of the great vessels: the role of diabetes. Stroke 1983;16:709-12.

92 Pullicino PM, Xuereb M, Aquiliana J, et al. Stroke following acute myocardial infarction in diabetics. $\mathcal{F}$ Intern Med acute myocardial

93 Palumbo PJ, Elveback LR, Whisnant JP. Neurological complications of diabetes mellitus: transient ischaemic attack, stroke, and peripheral neuropathy. Adv Neurol 1978;19: 593-601

94 Abbott RD, Donahue RP, MacMahon SW, et al. Diabetes and the risk of stroke: The Honolulu Heart Program. FAMA 1987;257:949-52.

95 Colwell JA, Bingham SF, Abraira C, et al. Veterans administration cooperative study on antiplatelet agents in diabetic patients after amputation for gangrene II: effects of aspirin and dipyramidole on atherosclerotic disease rates. Diabetes Care 1986;9:140-8.

96 Sagel J, Colwell J, Crook L, et al. Increased platelet aggregation in early diabetes mellitus. Ann Intern Med 1975;83: $733-8$
97 Silvenius T, Laako M, Riekkinen Sr P, et al. European stroke prevention study: effectiveness of antiplatelet therapy in secondary prevention of stroke. Stroke 1992;23:851-4.

98 Adams HP, Patman SF, Kassell NF, et al. Prevalence of diabetes mellitus among patients with subarachnoid hemorrhage. Arch Neurol 1984;41:1033-5.

99 Gough A, Clapperton M, Rolando N, et al. Randomized placebo-controlled trial of granulocyte colony stimulating factor in diabetic foot infection. Lancet 1997;350:855-9.

100 Darouiche RO, Hamill RJ, Greenberg SB, et al. Bacterial spinal epidural abscess: review of 43 cases and literature survey. Medicine 192;71:369-85.

101 Khanna RK, Malik GM, Rock JP, et al. Spinal epidural abscess: evaluation of factors influencing outcome. Neurosurgery 1996;39:958-64.

102 Smitherman KO, Peacock Jr JE. Infectious emergencies in patients with diabetes mellitus. Med Clin N Am 1995;79: 53-77

103 Larkin JG, Butcher JG, Frier BM, et al. Fatal rhinocerebral mucormycosis in a newly-diagnosed diabetic. Diabet Med 1986;3:266-8.

104 Doroghazi RM, Nadol JB, Hyslop NE, et al. Invasive external otitis. Report of 21 cases and review of the literature. Am f Med 1981;71:603-14.

105 Schwarz GA, Blumenkrantz MJ, Sundmaker WLH. Neurologic complications of malignant external otitis. Neurology 1971;21:1071-4.

106 Soler NG, Walsh CH, Malins JM. Congenital malformations in infants of diabetic mothers. Qf Med 1976;45:303-

107 Reece EA, Hobbins JC. Diabetic embryopathy. Obstet Gynecol Surv 1986;41:325-35.

108 Casson IF, Clarke CA, Howard CV, et al. Outcomes of pregnancy in insulin dependent diabetic women: results of a five year population cohort study. BMF 1997;315:275-8.

109 Milunsky A, Alpert E, Kitzmiller JL, et al. Prenatal diagnosis of neural tube defects. VII. The importance of alpha-fetoprotein screening in diabetic pregnant women. Am $\mathcal{F}$ Obstet Gynecol 1982;142:1030-2.

110 Mills JL, Baker L, Goldman AS. Malformation in infants of diabetic mothers occur before the seventh gestational week: implications for treatment. Diabetes 1979;28:292-3.

111 Kukera J. Rate and type of congenital abnormalities among offspring of diabetic women. 7 Reprod Med 1971;7:73-89.

112 Eriksson U, Styrud J. Congenital malformations in diabetic pregnancy. The clinical relevance of experimental animal studies. Acta Paediat Scand 1985;(suppl 320):72-8.

113 Diabetes Control and Complications Trial Research Group. Pregnancy outcomes in the diabetes control and complications trial. Am f Obstet Gynecol 1996;174:1343- 